\title{
O PRINCÍPIO DAS POSSIBILIDADES ALTERNATIVAS
}

\author{
Tania Schneider da Fonseca ${ }^{1}$ \\ Universidade do Vale do Rio dos Sinos (UNISINOS) \\ (iD) https://orcid.org/0000-0002-3701-8015 \\ E-mail: taniaschneider.fonseca@gmail.com.
}

\section{RESUMO:}

Com o seu artigo de 1969, "Alternate Possibilities and Moral Responsibility", Harry Frankfurt mudou o curso do debate sobre o problema da vontade livre. Ele forneceu exemplos hipotéticos, por meio de experimentos de pensamento, de agentes que, conforme ele argumentou, embora não pudessem ter agido de outro modo, ainda assim seriam moralmente responsáveis pelas suas ações. $\mathrm{O}$ artigo de Frankfurt entusiasmou muitos filósofos, destacadamente John Fischer, a repensar o problema da responsabilidade moral. Para Fischer, Frankfurt teria mostrado que o debate não diz mais respeito ao problema de demonstrar a compatibilidade entre liberdade e determinismo, mas, sim, à questão da compatibilidade da responsabilidade moral com o determinismo.

PALAVRAS-CHAVE: Responsabilidade moral; Liberdade; Determinismo.

\section{THE PRINCIPLE OF ALTERNATIVE POSSIBILITIES}

\begin{abstract}
:
In 1969, when "Alternative Possibilities and Moral Responsibility" (1969) was published, Harry Frankfurt changed the course of the discussion about the free will problem. Frankfurt showed, through some thought experiments, agents that, he argued, were moral responsible for their actions even though they could not have acted otherwise. Frankfurt's essay pushed several philosophers, remarkably John Fischer, to rethink the problem of moral responsibility. For Fischer, Frankfurt showed that the debate should not be about the compatibility between freedom and determinism, but rather should address the question of whether moral responsibility is compatible with determinism.
\end{abstract}

KEYWORDS: Moral Responsibility; Freedom; Determinism.

\footnotetext{
${ }^{1}$ Doutora em Filosofia pela Universidade do Vale do Rio dos Sinos (UNISINOS), São Leopoldo - RS, Brasil.
}

FONSECA, Tania Schneider da. O princípio das possibilidades alternativas. Griot : Revista de Filosofia, Amargosa - BA, v.19, n.2, p.230-249, junho, 2019. 
Neste artigo tratarei das posições compatibilistas e incompatibilistas sobre o determinismo e a liberdade. Primeiro apresentarei a posição de Frankfurt sobre a possibilidade do agente ser moralmente responsável apesar de não poder agir diferentemente. Depois, diferentes versões da teoria átimo de liberdade, proposta por filósofos que não ficaram convencidos pelo argumento de Frankfurt. Em seguida, será analisada a rejeição da abordagem átimo de liberdade por Fischer. Depois, uma réplica apresentada por filósofos conhecida como a defesa do dilema. E, por fim, a resposta de Fischer a essa nova tentativa de preservar a possibilidade do agente poder agir diferentemente para poder ser moralmente responsável pelo seu comportamento.

\section{A refutação de Frankfurt do princípio das possibilidades alternativas}

Existem vários desafios céticos à ideia intuitiva de que nós teríamos vontade livre no sentido que envolveria possibilidades alternativas. Um dos argumentos para a incompatibilidade da vontade livre e determinismo é conhecido como o "argumento da consequência". Segundo esse argumento, se determinismo causal é verdadeiro, então nossas ações são consequências das leis da natureza e eventos no passado remoto. Mas não está em nós o que se passou antes de nós nascermos; e nem está em nós o que são as leis da natureza. Portanto, as consequências dessas coisas (incluindo nossas próprias ações) não estão em nós (INW AGEN, 1983, p. 15).

Esse argumento emprega ingredientes do senso comum, como a fixidez do passado e das leis da natureza, para mostrar que nós não teríamos o tipo de controle que abrangeria cursos alternativos de ações. Um dos mais importantes desafios a essa ideia é oferecido pela doutrina do determinismo causal. Determinismo causal é "a tese que todo evento é deterministicamente causado por algum evento no passado; assim, toda a escolha e todo o comportamento é o resultado de uma cadeia causal" (FISCHER, 2006, p. 183). Nossas ações, escolhas e deliberações seriam eventos mecânicos naturais, como o são os movimentos das águas e das pedras.

Assim, supondo que o determinismo causal seja verdadeiro e que eu faça uma escolha $C$ no (tempo) $t_{2}$ :

Segue a partir da suposição do determinismo causal que o estado do mundo no $t_{1}$ juntamente com as leis da natureza implica que eu faço a escolha $C$ no $t_{2}$. Assim, em todos os mundos possíveis com as mesmas leis do mundo real [...] eu faço a escolha $C$ no $t_{2}$. É evidente que se determinismo causal é verdadeiro, eu não posso fazer qualquer outra escolha a não ser a que eu faço na realidade (FISCHER, 2006, p. 183).

Nem todos têm aceitado que esse argumento é sólido. Vários filósofos têm argumentado que nós poderíamos ter possibilidades alternativas mesmo em um mundo causalmente determinístico ${ }^{2}$. Porém, outros estão inclinados a aceitar o argumento que estabelece que se determinismo causal é verdadeiro, então nós não teríamos o tipo de controle que envolveria possibilidades alternativas. Esses filósofos acreditam que responsabilidade moral exigiria o poder para escolher ou agir diferentemente, além da necessidade da falsidade da tese determinista.

2 Ver Horgan (1979, 1985), Lewis (1981) e Bok (1998).

FONSECA, Tania Schneider da. O princípio das possibilidades alternativas. Griot : Revista de Filosofia, Amargosa - BA, v.19, n.2, p.230-249, junho, 2019. 
O argumento da consequência é defendido por incompatibilistas que não foram convencidos pelo argumento de Frankfurt contra o que ele denomina, em "Alternate Possibilities and Moral Responsibility" (1969), de princípio das possibilidades alternativas (PPA). Esse princípio pode ser formulado como se segue: "uma pessoa é moralmente responsável pelo o que fez apenas se ela poderia ter feito diferentemente" (FRANKFURT, 1998, p. 1). Seu significado é assunto de controvérsia, no entanto, escreveu Frankfurt, "praticamente ninguém parece inclinado a negar ou a questionar que o princípio das possibilidades alternativas (construído em alguma forma ou outra) é verdadeiro" (FRANKFURT, 1998, p. 1). Alguns filósofos têm o caracterizado como "uma verdade a priori".

Teorias podem fazer uso de exemplos de situações que envolvem coerção para anular o PPA. Elas podem afirmar que uma pessoa que tem sido coagida a fazer alguma coisa não poderia ter feito de outro modo; que ela não agiu livremente, e portanto, não poderia ser moralmente responsável pelo o que fez. Porém, para Frankfurt, a ausência de responsabilidade moral não estaria conectada com o fato de que a pessoa não poderia ter agido diferentemente. Ele argumenta que poderia existir alguma circunstância que não deixa alternativa para a pessoa, porém essa circunstância, na realidade, não desempenharia nenhum papel ou não conduziria ela a fazer o que ela faz. Frankfurt apresenta uma série de experimentos mentais, nos quais as situações são alteradas até que o agente não possua possibilidades alternativas, mas ainda assim age livremente, por sua própria vontade e poderia ser moralmente responsável pela ação exercida.

Exemplifico o ponto citando o personagem Jones, realizando a mesma ação, em quatro diferentes situações (FRANKFURT, 1998, p. 3-6). Vamos supor que alguém ameace Jones com certas penalidades caso ele não praticasse a ação exigida. Por exemplo, o oficial nazista entra na sua casa e ameaça prendê-lo e torturar a sua família caso ele não entregue o paradeiro do judeu, escondido no porão da sua casa. Jones poderia ser considerado responsável pela ação exercida nessas circunstâncias? Isso dependeria, segundo Frankfurt, do que realmente o levou a agir, se foi a sua decisão original ou a ameaça do oficial nazista. Imagine que Jones 1 seja um homem não razoável, que não se importa com as consequências das suas ações, pratica ação por sua própria vontade, faz o que já havia decidido, e uma vez que ele tenha tomado uma decisão nunca volta atrás, custe o que custar. Ele agiu sem levar em consideração a ameaça. Sendo assim, esse não seria um caso propriamente dito de coerção, visto que a ameaça feita não teria surtido efeito na tomada de decisão de Jones. Esse exemplo não representaria uma situação na qual o agente estaria sem alternativas para sua ação, pois é como se a ameaça não tivesse sido feita. Se ele tivesse decidido não revelar o paradeiro do judeu, a ameaça sofrida não o teria forçado a fazê-lo. Nesse caso, esse exemplo não seria um contraexemplo ao PPA.

Outra hipótese seria pensar a ação de Jones2 sendo resultado da coerção. Aterrorizado pela ameaça do oficial nazista, e em virtude dela, ele fez o que the foi exigido e entregou o paradeiro do judeu, independentemente da sua decisão tomada anteriormente à ameaça. $\mathrm{O}$ fato de que no tempo anterior Jonesz tenha decidido, por razões próprias, agir naquele modo poderia ser relevante para a avaliação do seu caráter, e "ele pode ser completamente responsável moralmente por ter feito essa decisão" (FRANKFURT, 1998, p. 3). Porém, nesse contexto dificilmente poderia ser 
dito que ele é moralmente responsável pela sua ação, considerando que ele a teria realizado simplesmente como resultado da coerção.

A terceira possibilidade seria aquela em que Jones 3 não agiria motivado pela ameaça (Jones 2$)$ nem seria indiferente à ela (Jones 1$)$. Assim como as suas contrapartes hipotéticas, Joneş realiza a mesma ação e entrega o paradeiro do judeu, porém Jones 3 agiu com base na sua decisão tomada antes da ameaça. Ele não estaria agindo motivado pelo medo da penalidade. A ameaça de fato não teria influenciado a realização da sua ação e o forçado a entregar o paradeiro do judeu, mas ela teria feito isso se ele já não tivesse motivo suficiente para realizar a ação em questão.

Esse caso mostra que o fato de que uma ameaça irresistível é feita não necessariamente implicaria que a pessoa que a recebe é coagida a fazer o que ela faz. A irresistibilidade da ameaça à qual Jones 3 está sujeito pode significar que não havia alternativa para ele a não ser exercer a ação que ele fez. Quer dizer, apesar da ameaça, isto é, embora ele não tivesse alternativas disponíveis, parece natural afirmar que ele é moralmente responsável pelo que fez, na medida em que ele teria agido a partir da sua própria vontade e não por causa da ameaça (FRANKFURT, 1998, p. 4).

Apesar do caso do Jones3 apresentar uma conclusão intuitiva, esse exemplo não convenceu a todos. A seguinte objeção pode ser feita: mesmo Jones 3 estando suscetível a ameaças, lhe restaria ainda uma possibilidade alternativa, pois ele poderia resistir à ameaça e aceitar a penalidade. Portanto, esse é um caso que seria difícil afirmar o que teria motivado a ação de Jones 3 : se a sua decisão anterior à ameaça ou a própria ameaça e o medo da penalidade.

Frankfurt acredita que essa não é uma boa objeção à sua defesa da falsidade do PPA. Para mostrar por que, ele altera a estrutura do exemplo:

Suponha que alguém, Black, quer que Jones 4 realize uma determinada ação. Black está preparado para intervir, mas ele prefere evitar agir desnecessariamente. Então, ele espera até que Jones pense o que fazer, e ele não faz nada a não ser que seja claro para ele (Black é um excelente juiz de tais coisas) que Jones $_{4}$ está decidindo fazer alguma coisa diferente do que ele quer que ele faça. Se se torna claro que Jones $_{4}$ está decidindo fazer alguma coisa diferente, Black tomaria as medidas eficazes para assegurar que Jones 4 decidiria fazer e que ele faria o que ele (Black) quer que Jones faça (FRANKFURT, 1998, p. 6).

Para ilustrar esse caso, imaginemos que Black, trabalhando no partido dos democratas, quer que Jones 4 escolha e vote em Hillary Clinton, nas eleições de novembro de 2016 nos EUA, e não em Donald Trump, candidato do partido republicano. Black fará o que for necessário para garantir que Jones4 decida votar e vote em Clinton. Vamos imaginar que Black manipule o processo cerebral de Jones4 (por meio de algum dispositivo instalado em seu cérebro) de modo a determinar a sua escolha e o seu voto. Dado essa condição, Jones4 não pode fazer de outro modo. Agora suponha que Black não tenha precisado intervir porque Jones4 decidiu e realizou, por razões próprias, a ação que Black desejava. Sendo assim, parece claro que Jones4 manterá a mesma responsabilidade pela sua ação que teria se tivesse feito o mesmo sem a presença do dispositivo de Black. Não seria razoável desculpar Jones4

FONSECA, Tania Schneider da. O princípio das possibilidades alternativas. Griot : Revista de Filosofia, Amargosa - BA, v.19, n.2, p.230-249, junho, 2019. 
pela sua ação alegando que ele não poderia ter feito de outro modo, pois esse fato não influenciou a sua ação. Ele teria agido do mesmo modo sem a presença do dispositivo instalado em seu cérebro por Black (FRANKFURT, 1998, p. 7).

A ideia central, segundo Frankfurt, é observar a existência de condições suficientes para a realização da ação de Jones4. Significa que Jones4 não teria possibilidades alternativas porque ele exerce a ação desejada por Black. A atribuição de responsabilidade dependeria de qual teria sido a motivação da ação (se se trata de sua própria predisposição ou de uma intervenção de Black). Agindo por razões próprias ou agindo por influência de Black, a ação seria a mesma. Se ele age por razões próprias "sua responsabilidade moral por essa ação não é afetada pelo fato de Black estar à espera com planos sinistros, visto que essa intenção não teve nenhum papel na realização da ação" (FRANKFURT, 1998, p. 8).

Os exemplos discutidos por Frankfurt não são exatamente morais, então podemos reapresentá-los de uma maneira a evidenciar a responsabilidade especificamente moral dos agentes envolvidos. Podemos imaginar um cenário envolvendo um assassino. Reusando os personagens Jones e Black, digamos que Black quer que Jones mate o prefeito da cidade. Black espera Jones tomar a sua decisão. Se Black percebe que Jones está decidindo não matar o prefeito, ele intervirá para assegurar que Jones decida e execute a ação pretendida. Porém, Jones decidiu, por razões próprias, matar o prefeito, e Black não precisou intervir.

$O$ fato de que uma pessoa não poderia ter evitado fazer uma determinada ação é uma condição suficiente para ela ter feito. Porém, como mostra esse último exemplo, esse fato (ela não poderia ter feito de outro modo) pode não desempenhar qualquer papel na explicação do por que ela agiu. Quer dizer, "embora a pessoa fosse incapaz de fazer de outro modo, pode não ser o caso de que ela agiu porque não poderia ter feito de outro modo" (FRANKFURT, 1998, p. 8). Agora se uma pessoa não tinha alternativa para realizar uma certa ação, mas não a realizou porque era incapaz de fazer de outro modo, então ela teria realizado a mesma ação mesmo se ela poderia ter feito de outro modo.

O equívoco do princípio das possibilidades alternativas estaria na pressuposição de que uma pessoa não é moralmente responsável por ter realizado uma ação se havia circunstâncias que tornaram impossível para ela evitar de realizála. Desse modo, o princípio das possibilidades alternativas poderia ser revisado de modo a declarar "que uma pessoa não é moralmente responsável pelo o que ela fez se ela o fez porque ela não poderia ter feito de outro modo" (FRANKFURT, 1998, p. 9).

Pode ser observado que essa revisão do princípio não necessariamente afeta os argumentos daqueles que contam com o princípio original nos seus esforços para defender o incompatibilismo da responsabilidade moral com o determinismo. Se foi causalmente determinado que uma pessoa realiza uma certa ação, então será verdadeiro que ela a realizou por causa desses determinantes causais. E se o fato de que foi causalmente determinado que ela realizou uma determinada ação significa que ela não poderia ter feito de outro modo (como supõem os argumentos incompatibilistas), então o fato de que foi causalmente determinado que uma pessoa realizou uma certa ação significará que a pessoa agiu porque não poderia ter feito de outro modo. O princípio das possibilidades alternativas "revisado" implicaria, nesse 
caso, que uma pessoa não é moralmente responsável pelo o que ela fez se o que ela fez foi causalmente determinado. Frankfurt não acredita que essa revisão do princípio seja aceitável:

\begin{abstract}
Imaginemos que uma pessoa nos diga que ela fez o que ela fez porque ela era incapaz de fazer de outro modo; ou que essa pessoa faça uma afirmação similar, a de que fez o que fez porque ela tinha de fazer o que ela fez. Nós frequentemente aceitamos essas justificativas como desculpas válidas (se nós acreditamos nelas), e elas podem bem parecer, à primeira vista, invocar o princípio revisado das possibilidades alternativas. Porém, eu penso que quando nós aceitamos tais afirmações como desculpas válidas é porque nós assumimos que o que está sendo dito é mais do que o que as afirmações, literalmente, dizem (FRANKFURT, 1998, p. 9-10).
\end{abstract}

Quer dizer, quando a pessoa oferece tais justificativas, nós entendemos que ela quer significar que ela fez o que ela fez apenas porque ela era incapaz para fazer de outro modo, ou apenas porque ela tinha de fazer o que ela fez. Além disso, entendemos, mais particularmente, que ela quer significar que ela fez o que ela fez não porque isso era o que ela, na realidade, queria fazer. Assim, o princípio deveria ser substituído pelo seguinte princípio "uma pessoa não é moralmente responsável pelo o que ela fez se ela o fez unicamente porque ela não poderia ter feito diferentemente" (FRANKFURT, 1998, p. 9-10). Esse novo princípio não pareceria entrar em conflito com a visão de que responsabilidade moral é compatível com o determinismo.

A questão que imediatamente surge é se Frankfurt refutou, de modo satisfatório, o PPA. Enquanto alguns filósofos foram persuadidos de que nós deveríamos rejeitar o PPA, muitos não foram convencidos, seja pelos argumentos de Frankfurt, seja pelos defensores do compatibilismo de tipo Frankfurt (FISCHER, 2010a, p. 317).

\title{
A estratégia átimo de liberdade [flicker of freedom]
}

Alguns céticos rejeitam a ideia de que Frankfurt tenha fornecido casos em que o agente seria moralmente responsável apesar de não poder agir diferentemente. Eles insistem que nós não somos forçados pelos casos de tipo Frankfurt a desistir do PPA. Outros céticos estão dispostos a abandonar o PPA, mas argumentam que o determinismo causal eliminaria a responsabilidade moral por alguma outra razão. $O$ primeiro grupo de céticos, aqueles que insistem que nos exemplos de tipo Frankfurt há possibilidades alternativas, defendem uma estratégia conhecida como átimo de liberdade. Embora existam várias versões distintas dessa estratégia, elas defendem o mesmo argumento, a saber, de que apesar da impressão inicial de que nos casos de tipo Frankfurt não haveria possibilidades alternativas, de fato alguém poderia perceber que existem nesses casos tais possibilidades alternativas, ainda que mínimas. Embora o interventor contrafactual, Black, eliminaria a maioria dos cursos alternativos de ações, ele não excluiria todos. A crítica que estaria por trás dessa estratégia seria a de que Frankfurt não teria justificado adequadamente a compatibilidade da responsabilidade com o determinismo. Subjacente a essa crítica estaria a visão tradicional de que se o determinismo ameaçaria a responsabilidade

FONSECA, Tania Schneider da. O princípio das possibilidades alternativas. Griot : Revista de Filosofia, 
seria em virtude de enfraquecer o tipo de controle correspondente às possibilidades alternativas. Irei apresentar três versões dessa estratégia, e depois uma réplica que procura identificar um problema que seria comum a todas elas.

(a) Caso A

Um dos pontos de interesse no debate sobre os casos de Frankfurt foi a investigação de como Black saberia como Jones irá agir. A literatura posterior à publicação do artigo de Frankfurt introduziu a possibilidade da existência de um "sinal anterior" que poderia ser lido pelo interventor contrafactual ${ }^{3}$, o qual o auxiliaria na sua atividade (FISCHER, 2002, p. 282). Com base nos exemplos de tipo Frankfurt, nós podemos imaginar um caso em que Jones teria uma inclinação para mostrar algum sinal que indicaria em quem ele irá votar, antes mesmo de começar a fazer uma escolha ou antes de formar uma intenção. Suponha que Jones levantasse a sobrancelha antes de começar qualquer processo de tomada de decisão se e somente se ele estivesse prestes a escolher votar em Trump. Supondo que isso seja assim, então Black poderia, ao ler o sinal, impedir Jones de começar a fazer tal escolha ou decisão. Nesse caso, um átimo de liberdade emerge, pois Jones teria o poder para mostrar o sinal antes de começar a escolher, como o franzir da sobrancelha ${ }^{4}$. Sem um átimo de liberdade, Black não poderia prever o que Jones faria.

(b) Caso B

Para Inwagen, mesmo que o argumento de Frankfurt contra o PPA seja sólido, existem ainda três princípios que se não são versões desse princípio, são muito similares a ele. $O$ ponto básico seria observar que os defensores dos exemplos de tipo Frankfurt não são precisos em especificar pelo o quê o agente é moralmente responsável. $O$ agente seria moralmente responsável, segundo a posição do autor, não apenas por atos realizados, mas também por atos não realizados (omissões) e pelas consequências do que ele fez ou deixou de fazer.

$\mathrm{O}$ argumento pretende mostrar que os seguintes três princípios são imunes aos contraexemplos de tipo Frankfurt ao PPA. São esses:

Princípio da Ação Possível (PAP): Uma pessoa seria moralmente responsável por deixar de realizar um dado ato apenas se ela poderia ter realizado esse ato $^{5}$.

Princípio da Prevenção Possível (PPP1): Uma pessoa seria moralmente responsável por um certo evento (particular) apenas se ela poderia tê-lo evitado (INWAGEN, 1978, p. 206).

\footnotetext{
${ }^{3} \mathrm{O}$ termo "interventor contrafactual" foi introduzido por Fischer (1982).

${ }^{4}$ David Blumenfeld desenvolveu este exemplo de tipo Frankfurt (1971, p. 339-345).

${ }^{5}$ Sobre PAP, Inwagen nos pede para imaginar uma situação em que ele está na janela da sua casa quando testemunha a cena de um crime. Diante dessa situação, talvez seja melhor chamar a polícia. Então, ele pega o telefone, mas coloca de volta no gancho. Ele pensa por um momento e percebe que se ligar para a polícia, o criminoso talvez o ouça e queira se vingar. De qualquer forma, provavelmente o policial pedirá para ele se deslocar até a delegacia para fazer uma ocorrência, e como já é quase meia noite e no outro dia ele precisa levantar cedo, ele decide "não se envolver". Agora, suponha que, sem o seu conhecimento, houve algum tipo de interrupção nos serviços da central telefônica e nenhum telefone da cidade está funcionando e permanecerá assim por várias horas. $O$ ponto é que ele não seria responsável por não ter comunicado a polícia sobre o ocorrido, pois ele não poderia ter feito. Ele poderia ser responsável por não ter tentado chamar a polícia, pois isso ele poderia ter feito (INW AGEN, 1978, p. 204-205).
}

FONSECA, Tania Schneider da. O princípio das possibilidades alternativas. Griot : Revista de Filosofia, Amargosa - BA, v.19, n.2, p.230-249, junho, 2019. 
Princípio da Prevenção Possível (PPP2): Uma pessoa seria moralmente responsável por um certo estado de coisas apenas se (esse estado de coisas ocorre e) ela poderia ter o impedido de ocorrer (INWAGEN, 1978, p. 210, 220).

PAP diz respeito aos atos não realizados, PPP1 às consequências do que o agente fez e PPP2 às consequências do que o agente deixou de fazer. A diferença entre PPP1 e PPP2 está no estatuto ontológico: o primeiro é sobre eventos e o segundo é sobre estado de coisas. PPP1 se aplicaria às consequências consideradas como eventos particulares e PPP2 às consequências consideradas como eventos universais ${ }^{6}$.

Sobre o PPP2, Inwagen desenvolve um caso em que o agente não poderia ter impedido um estado de coisas de ocorrer, o que implicaria que ele não poderia ser moralmente responsável. Por exemplo, suponha que o cavalo de Ryder, Dobbin, saiu em disparada. Dobbin responde ao freio, e em cada encruzilhada Ryder pode guiar Dobbin ou para a direita ou para a esquerda. Sem que Ryder saiba, ambas as ruas em uma encruzilhada levam para Roma. Ryder poderia, nesse caso, ser responsável por guiar Dobbin para a esquerda ou para a direita, mas não seria razoável dizer que ele seria responsável pelo fato de que ele passa por Roma (INWAGEN, 1983, p. 177; 1978, p. 216-217). Na intuição de Inwagen, "parece óbvio que ele não é responsável por esse estado de coisas apenas porque ele não poderia ter impedido" (INW AGEN, 1978, p. 217). Dobbin e Ryder teriam passado por Roma, independentemente de ir pela esquerda ou pela direita.

Agora sobre o princípio das possibilidades alternativas aplicado às consequências-particulares:

PPP1: Uma pessoa é moralmente responsável por um certo evento (particular) apenas se ela poderia tê-lo evitado.

Inwagen questiona se o seguinte contraexemplo de tipo Frankfurt poderia ser construído contra esse princípio:

Black atira e mata Jones (intencionalmente), portanto, produzindo sobre a morte de Jones um certo evento. Mas existe algum fator $F$ que (i) desempenhou nenhum papel causal na morte de Jones, e que (ii) teria causado a morte de Jones se Black não tivesse atirado nele (visto que o fator $\mathrm{F}$ pode ter causado a morte de Jones ao causar Black a atirar nele, talvez nós deveríamos dizer "se Black não tivesse decidido atirar nele"), e (iii) é tal que Black não poderia ter impedido de causar a morte de Jones exceto por matar (ou decidir matar) ele mesmo a Jones. Pareceria que

\footnotetext{
${ }^{6}$ Entre os filósofos que acreditam que nós responsabilizamos os agentes por eventos de certos tipos, existe um desacordo em relação ao status ontológico desses eventos. Eles devem ser construídos como universais ou como particulares? (FISHER, 2006, p. 28) Para evitar tomar partido nesse debate, Inwagen usa a seguinte estratégia: indica um certo princípio para eventos ou estado de coisas pelo qual nós responsabilizamos as pessoas como particular e outro princípio para eventos ou estado de coisas como universal (INW AGEN, 1978, p. 206).
}

FONSECA, Tania Schneider da. O princípio das possibilidades alternativas. Griot : Revista de Filosofia, Amargosa - BA, v.19, n.2, p.230-249, junho, 2019. 
Black é responsável pela morte de Jones, embora ele não poderia ter impedido a morte de Jones (INWAGEN, 1978, p. 210)7.

É facilmente perceptível, na perspectiva do autor, que essa história é inconsistente (INWAGEN, 1978, p. 210). Podemos adaptar esse contraexemplo de tipo Frankfurt para ver com mais clareza o que estaria por trás dessa versão da estratégia apresentada por Inwagen. Assim, teríamos que, na sequência real, Jones escolhe votar e vota em Clinton. Agora, imagine que Jones comece a mostrar uma inclinação (envolvendo um sinal anterior diferente) de escolher votar em Trump e isso provocaria a intervenção de Black, e a subsequente escolha para votar (e a concretização dessa escolha) em Clinton. Sob tais hipóteses, Jones teria votado em Clinton.

Partindo de uma distinção entre sequência real e sequência alternativa, se Jones não tivesse votado em Clinton, e como resultado o fator $\mathrm{F}$ tivesse causado Jones a votar em Clinton, então teria ocorrido um evento denotado "votar em Clinton" que teria o fator F como uma de suas causas. Esse evento teria sido diferente do evento "votar em Clinton" na sequência real, resultante das próprias deliberações de Jones $^{8}$. No final das contas, o evento na sequência real não teria ocorrido (INWAGEN, 1978, p. 210).

Mais especificamente, essa abordagem adota o seguinte princípio para identificar e individualizar eventos particulares: " $x$ é o mesmo evento $y$ se e apenas se $x$ e $y$ têm as mesmas causas"9. Usando esse critério, Jones teria causado um evento particular diferente quando ele vota em Clinton, na medida em que a causa seria a intervenção de Black. Supondo que Black não desempenhou qualquer papel no evento da sequência real, mas exerceu um tal papel no cenário alternativo, dado o princípio da individualização, o evento real particular não poderia ser idêntico ao evento hipotético da sequência alternativa. Portanto, Jones possuiria o poder para produzir um evento particular diferente, ele poderia evitar que o evento particular, na sequência real, ocorresse. Aí estaria o átimo de liberdade (INWAGEN, 1978, p. 206-208). Se responsabilidade pela ação, de fato, envolve responsabilidade por provocar um evento particular concreto, então responsabilidade pela ação envolveria possibilidades alternativas.

(c) Caso C

A terceira versão da estratégia do átimo de liberdade está associada à posição libertista $^{10}$. $\mathrm{O}$ que distinguiria uma ação de um mero evento seria que a ação é

\footnotetext{
${ }^{7}$ Eu adaptei os personagens de Inwagen ao caso original de Frankfurt.

8 Aqui pode ser adotado a seguinte suposição: quando o agente realiza uma ação, ele causa a ocorrência de algum evento.

9 O ponto é encontrar um modo para saber, de um dado evento, se esse mesmo evento teria ocorrido se as coisas tivessem sido diferentes (INWAGEN, 1978, p. 207). O princípio para individualizar eventos deve fornecer um modo de identificar eventos por meio de mundos possíveis, isto é, individualizar que um evento $A$ no mundo alfa é o mesmo evento particular $B$ no mundo beta apenas se $A$ e $B$ tem os mesmos antecedentes causais (FISCHER, 1982, p. 29). Inwagen parte de critério de Donald Davidson, com alguma modificação, para individualizar eventos. Para Davidson, $x$ e $y$ são os mesmos eventos se e apenas se $x$ e $y$ tem as mesmas causas e efeitos (INWAGEN, 1978, p. 207).

10 Existem diferentes versões da posição libertista que procuram dar explicações de como preencher o espaço aberto pelo indeterminismo. Muitos libertistas modernos, por exemplo, argumentam que nós alcançamos autodeterminação, em um mundo indeterminístico, ao sermos nós mesmos os determinantes de nossas ações
}

FONSECA, Tania Schneider da. O princípio das possibilidades alternativas. Griot : Revista de Filosofia, Amargosa - BA, v.19, n.2, p.230-249, junho, 2019. 
precedida por uma volição ${ }^{11}$. Partindo da intuição básica dessa explicação libertista, a volição deveria ser causada pelo agente ${ }^{12}$. $\mathrm{O}$ ponto é que quando um agente causa uma volição por esse tipo de relação causal, isso significaria que nenhum fator externo faz com que o agente cause a volição (FISCHER, 2006, p. 43-44).

Adotando essa explicação no caso de tipo Frankfurt, teríamos que Jones delibera, escolhe e age no modo normal. Vamos supor que Jones cause a sua volição para votar em Clinton. Agora imagine a sequência alternativa. Suponha que tão logo Jones começasse a mostrar uma inclinação para escolher votar em Trump, Black interferiria e asseguraria que ele escolhesse votar em Clinton. Sob tais circunstâncias, Jones teria algum tipo de estado mental consistindo em uma escolha para votar em Clinton, mas ele não teria causado uma volição para votar nesse candidato, na medida em que sua volição foi causada por um fator externo. Assim, de acordo com a análise libertista, embora Jones não tivesse o poder para causar uma volição para votar em Trump, ele teria um átimo de liberdade, pois ele possuiria o poder de abster-se de causar uma volição para votar em Clinton. Nessa abordagem, não é pressuposto que Jones deveria ter o poder para agir de outro modo ou mesmo formar um tipo diferente de volição para ser considerado moralmente responsável pelo o que faz, mas Jones deveria ter o poder de não formar o tipo de volição que ele, na realidade, forma ${ }^{13}$.

\section{A rejeição da abordagem átimo de liberdade}

O argumento que será apresentado a seguir contra a estratégia átimo de liberdade pode ser aplicado a todas as versões apresentadas anteriormente. É mais conveniente começar com a posição de Inwagen, e então estender a crítica às outras visões. Porém, antes de apontar o suposto equívoco, eu gostaria de esclarecer sobre o tipo de controle que tem sido tradicionalmente adotado como condição necessária para atribuições de responsabilidade moral.

O problema com a estratégia átimo de liberdade, em todas as suas variantes, seria que ela baseia-se em uma incompreensão do PPA. Observe que na visão clássica, liberdade implicaria que o agente teria uma escolha entre dois ou mais cenários. Em um destes cenários, o agente deliberaria e formaria uma intenção para realizar um ato de um certo tipo e, então, realizaria essa intenção de um modo apropriado. No outro cenário possível, ele deliberaria e formaria uma intenção para realizar um diferente tipo de ato e, então, efetuaria essa intenção apropriadamente. Isso é o que estaria envolvido em ter possibilidades alternativas robustas, e esse seria certamente o modo natural de se pensar sobre o tipo de alternativas no qual a

(CHISHOLM, 2013, p. 26-37). Outros, como David Wiggins e Robert Kane, defendem uma posição libertista sem apelar para a teoria de que a causa da ação é o agente. Ver, Wiggins (2013, p. 94-121) e Kane (2013, p. 299-321).

11 Esta afirmação não necessita conduzir à visão libertista (FISCHER, 2006, p. 43).

12 A ideia básica que está por trás da posição que defende o agente como sendo a causa da sua ação seria de que ele poderia iniciar novas cadeias causais que não são pré-determinadas por eventos anteriores do passado ou pelas leis da natureza.

${ }^{13}$ Para Fischer não há necessidade de postular volições ou teorias baseadas no agente como sendo causa da ação para obter o tipo de resultado já esboçado. Assim, alguém poderia dizer que, embora Jones não tivesse o poder para escolher de outro modo, ele teria de fato o poder para abster-se de escolher votar em Clinton (FISCHER, 2006, p. 44).

FONSECA, Tania Schneider da. O princípio das possibilidades alternativas. Griot : Revista de Filosofia, Amargosa - BA, v.19, n.2, p.230-249, junho, 2019. 
responsabilidade moral estaria baseada. É evidente que esse tipo de liberdade não está presente nos contraexemplos de tipo Frankfurt (FISCHER, 2006, p. 47).

Agora sobre os casos apresentados anteriormente. Embora possa existir uma possibilidade alternativa, ela não seria suficientemente robusta para basear atribuições de responsabilidade moral. Desse modo, é implausível supor que seria em virtude da existência de uma tal possibilidade alternativa que um agente poderia ser moralmente responsável pelo o que faz. Seria preciso que a estratégia átimo de liberdade demonstrasse que essa possibilidade alternativa desempenha um certo papel no entendimento apropriado dos casos.

Retomando a ideia presente no princípio da prevenção possível, defendida por Inwagen, um agente seria moralmente responsável por um certo evento (particular) apenas se ele poderia tê-lo evitado. Mais especificamente, responsabilidade moral estaria conectada à ideia da possibilidade da ocorrência de um diferente evento. Partindo da distinção entre sequência real e sequência alternativa, dois eventos distintos resultariam, um tendo como causa um fator externo e outro tendo como causa as próprias deliberações do agente.

Mesmo que seja admitida a ocorrência, na sequência alternativa, de um evento diferente daquele que teria ocorrido na sequência real, é evidente que o agente, no cenário alternativo, não estaria agindo livremente. Parece estranho que o acréscimo de um cenário alternativo, em que a causa da ação é exterior e não resultante da escolha do agente, seria suficiente para tornar verdadeiro que ele possui o tipo de controle relevante necessário para responsabilizá-lo moralmente pelo dado evento (FISCHER, 2006, p. 45-46).

Suponha que aceitemos o seguinte princípio de Inwagen: " $x$ é o mesmo evento $y$ se e apenas se $x$ e $y$ têm as mesmas causas". Então, poderia ser estabelecido que um diferente evento teria ocorrido na sequência alternativa, visto que esse evento possui uma causa diferente. Mas o problema é que Inwagen não teria justificado adequadamente que o agente teria controle deliberativo. Ele estaria confundindo a "capacidade" de agir diferentemente com a "possibilidade" de alguma coisa diferente ocorrer $^{14}$. $\mathrm{O}$ equívoco cometido seria pensar que a única forma que o contraexemplo de Frankfurt poderia ameaçar o PPA seria apresentar um cenário alternativo em que o evento particular ocorrido é o mesmo da sequência real. Assim, "os casos de tipo Frankfurt não seriam melhor construídos como casos de acesso a um diferente mundo com o mesmo evento-particular, mas da falta de acesso ao tipo relevante de mundo alternativo" (FISCHER, 2002, p. 288).

A mesma objeção poderia ser feita à versão libertista $(\mathrm{C})$. Nesta perspectiva, para que o agente possa ser moralmente responsável ele deveria ter o poder de não causar a volição que ele, na realidade, causa. Suponha que Jones tenha o poder de não causar a volição para votar em Clinton, como visto anteriormente. Observe que Jones, mesmo nesse caso, não formaria na sequência alternativa uma intenção para abster-se de causar uma volição para votar em Clinton e, então, procederia para realizar essa intenção. Embora possa ser admitido que Jones tenha o poder de não

\footnotetext{
14 Inwagen insiste que Frankfurt não teria dissociado responsabilidade de controle e, sendo assim, não teria demonstrado que a responsabilidade é compatível com determinismo. O que estaria por trás dessa crítica é a visão tradicional de que, se determinismo ameaçaria a responsabilidade, seria em virtude de enfraquecer a liberdade enquanto capacidade para agir diferentemente (FISCHER, 1982, p. 32-33).
}

FONSECA, Tania Schneider da. O princípio das possibilidades alternativas. Griot : Revista de Filosofia, Amargosa - BA, v.19, n.2, p.230-249, junho, 2019. 
causar a volição para votar nesse candidato, o ponto é que ao não causar uma tal volição, ele não estaria agindo livremente. Por causa da intervenção de Black, Jones não teria se abstido de causar essa volição livremente. Mesmo se existisse alguma possibilidade alternativa aqui, de novo, ela não pareceria ser suficientemente robusta para basear atribuições de responsabilidade moral (FISCHER, 2006, p. 47).

$\mathrm{E}$, por último, a primeira estratégia poderia insistir que apesar do agente, na sequência alternativa, não poder escolher ou agir livremente, existe alguma coisa, nesse cenário, que seria feita livremente, isto é, Jones poderia começar a iniciar um processo para fazer uma escolha. Ele poderia, por exemplo, começar a escolher votar em Trump, ou poderia ter o poder de exibir algum sinal ou padrão neurológico diferente. Nesse sentido, a possibilidade de começar a escolher, a qual poderia ser considerada como sendo feita livremente, seria o que basearia as atribuições de responsabilidade moral.

Vejamos essa versão da estratégia para que possamos ver qual seria o problema que ela também apresentaria. Suponha que Jones esteja na cabine de votação deliberando em qual dos partidos ele deveria votar, se nos republicanos ou nos democratas. Caso Jones esteja prestes a votar em Trump, um dispositivo instalado no seu cérebro seria ativado fazendo com ele escolhesse votar e votasse em Clinton (FISCHER, 1999, p. 109-110). A questão que imediatamente surge é esta: como o dispositivo informaria a Black em qual candidato Jones estaria prestes a escolher votar? Um papel crucial seria desempenhado por algum tipo de sinal involuntário que indicaria as escolhas futuras do agente. Por exemplo, um franzir a testa, que meramente ocorreria nele e que não estaria sobre seu controle voluntário. John Fischer, um dos defensores dos casos de tipo Frankfurt, faz a seguinte observação:

Pode ser objetado que apesar da aparência incial Jones tem alguma
possibilidade alternativa. Embora Jones não pode escolher ou votar
diferentemente, ele pode exibir um diferente padrão neurológico no seu
cérebro. Eu tenho chamado uma tal possibilidade alternativa um átimo de
liberdade [...]. Mas eu afirmo que a mera exibição involuntária de algum
sinal - tal como um padrão neurológico no cérebro, um corar, ou um
franzir de testa, é insuficiente como uma base para a responsabilidade
moral. O poder involuntário para exibir um diferente sinal parece para
mim ser insuficientemente robusto para basear nossas atribuições de
responsabilidade moral (FISCHER, 2002, p. 288-289).

Dito de outra forma, se em $t_{2}$ Jones estivesse prestes a escolher votar em Clinton em t3, então um sinal involuntário teria sido exibido (por exemplo, o franzir da sobrancelha esquerda, ou algum padrão neurológico no seu cérebro) em $t_{1}$. Nesse caso, o dispositivo não seria ativado porque esse é o candidato no qual Black queria que Jones votasse. Mas se Jones tivesse mostrado outro sinal involuntário, então esse padrão neurológico (indicativo de que ele votaria em Trump) teria ativado o dispositivo de Black para intervir e fazer com que Jones escolha em t 2 votar em Clinton e com que ele vote em Clinton em $\mathrm{t}_{3}$ (FISCHER, 1999, p. 110).

$O$ ponto é que na sequência alternativa, na qual Jones mostraria um distinto padrão neurológico como um indicativo de uma escolha para votar em Trump, o sinal exibido seria completamente involuntário e a subsequente escolha e ação seriam

FONSECA, Tania Schneider da. O princípio das possibilidades alternativas. Griot : Revista de Filosofia, Amargosa - BA, v.19, n.2, p.230-249, junho, 2019. 
produzidas eletronicamente. Sendo assim, não poderia ser dito de modo razoável que no cenário alternativo Jones escolheria e agiria livremente, pois tanto a sua escolha quanto a sua ação não seriam resultantes do seu próprio raciocínio prático. Além disso, ele não poderia ser moralmente responsável de maneira apropriada por esse comportamento (FISCHER, 1999, p. 110-111). Ademais, "o demonstrativo de um tal sinal não é nem mesmo uma ação e certamente não plausivelmente pensado ser robusto suficiente para basear atribuições de responsabilidade moral" (FISCHER, 2006, p. 48).

Os exemplos de tipo Frankfurt, embora possam parecer bizarros ou incomuns, pretendem ser construídos para a finalidade de apontar que a responsabilidade moral depende do que acontece na sequência real e não do que acontece na sequência alternativa (FISCHER, 2006, p. 58-59). Para que o argumento de Frankfurt contra o PPA seja refutado, seria necessário mostrar que o átimo de liberdade, presente nos exemplos vistos acima, seja um ato voluntário suficientemente robusto.

Obviamente que nem todos ficaram convencidos de que nós poderíamos abandonar a visão tradicional de liberdade enquanto capacidade para agir diferentemente. Uma outra objeção, conhecida como a defesa do dilema ${ }^{15}$, pode ser vista como uma das ferramentas mais potentes dos céticos que negam que os casos de tipo Frankfurt tenham refutado o PPA de modo satisfatório.

\section{A defesa do dilema}

Como vimos anteriormente, a estratégia átimo de liberdade é um argumento em defesa da presença de possibilidades alternativas nos casos de tipo Frankfurt. Portanto, de acordo com essa visão, Frankfurt não teria dissociado responsabilidade de liberdade. Entretanto, a característica distintiva para o argumento que será tratado agora, a defesa do dilema, remete à relação entre o sinal anterior, exibido em $t_{1}$, pelo dispositivo neurológico, e a escolha ou ação, em $t_{2}$. Essa relação seria problemática, pois ela seria ou determinística ou indeterminística.

Vamos supor que a relação entre o sinal anterior e a escolha é indeterminista e Black somente irá interceder se for necessário. Digamos que Black percebe o franzir da sobrancelha esquerda de Jones, em $t_{1}$, e aguarda ele escolher, em $t_{2}$, votar em Clinton por razões próprias. Poderia ser pensado que se houvesse um pequeno espaço de tempo entre o sinal e a escolha de Jones, Black poderia interferir para impedir a concretização da escolha. Porém, o problema dessa versão do dilema é que embora o sinal anterior exibido pelo dispositivo neurológico seja confiável, pressupondo o indeterminismo seria possível que Jones começasse a escolher votar em Trump mesmo que ele tenha exibido o sinal relevante (de que iria escolher votar em Clinton) (FISCHER, 2010a, p. 319-320). Dado a hipótese da possibilidade do indeterminismo causal, parece que Black não poderia eliminar todas as possibilidades alternativas, pois Jones teria a possibilidade de "começar a fazer uma escolha", o que seria mais robusta do que um mero átimo de liberdade (FISCHER, 2002, p. 291). Além disso, embora a possibilidade de começar a escolher diferentemente possa ser bloqueada antes de ser concluída, seria, no entanto, um episódio voluntário. Sendo assim, ainda

15 Esta objeção foi desenvolvida por Robert Kane (1985), David Widerker (1995), Carl Ginet (1996) e Keith Wyma (1997).

FONSECA, Tania Schneider da. O princípio das possibilidades alternativas. Griot : Revista de Filosofia, Amargosa - BA, v.19, n.2, p.230-249, junho, 2019. 
não teríamos um contraexemplo ao PPA. Seria a existência da possibilidade de começar a escolher de outro modo que tornaria Jones moralmente responsável tanto pela sua escolha quanto pela sua ação.

Agora sobre a relação determinística entre o sinal prévio e a escolha ou ação. Nesse caso, parece que Jones não poderia escolher ou agir diferentemente. Digamos que Jones, em $t_{1}$, levantasse a sobrancelha direita, como indicativo de que ele escolheria votar em Trump em $t_{2}$, e de que ele votaria em Trump em $t_{3}$. Black, ao tomar conhecimento desse padrão neurológico em $t_{1}$ poderia impedir que Jones escolhesse ou votasse em Trump. Partindo da pressuposição sobre a existência do determinismo, o cético insistirá que nós não poderíamos afirmar que Jones é moralmente responsável por sua escolha e ação (FISCHER, 2002, p. 290). A compatibilidade do determinismo com a responsabilidade não seria justificada de modo adequado. De novo, ainda não teríamos um caso em que poderíamos dizer que o agente é moralmente responsável apesar de não poder agir de outro modo.

Apresentarei, a seguir, as objeções feitas por Robert Kane, David Widerker e Stewart Goetz ao contraexemplo de Frankfurt ao PPA.

(a) Kane, Widerker e Goetz

Robert Kane desenvolveu a seguinte versão do dilema:

\begin{abstract}
Imagine o que deve ser feito para exercer o controle de Frankfurt sobre a escolha de uma pessoa. O controlador, Black, planeja que Jones faça A. Mas se ele espera para ver se Jones está indo fazer A por razões próprias e unicamente intervém se Jones está prestes a fazer B....[a não ser que nós assumimos que a ação em questão é causalmente determinada], o controlador não pode saber qual delas vai ocorrer antes a não ser que ele predetermina uma delas a ocorrer. Ele pode, portanto, esperar até que ele descubra se o agente fará $\mathrm{A}$ ou $\mathrm{B}$, mas então é tarde demais para controlar a escolha. Ou ele pode intervir no cérebro desligando a indeterminação ou seus efeitos antes que qualquer escolha ocorra, determinando, portanto, o resultado que ele deseja. No último caso, a escolha será determinada pelo controlador e o controlador, e não o agente, será responsável por isso [...] Por contraste, se o controlar não intervém para predeterminar o resultado, e a indeterminação permanece no lugar até que a escolha seja feita [...] então o agente, e não o controlador, é responsável por isso. Mas então é também o caso de que o agente poderia ter feito de outro modo (KANE, 1998, p. 142).
\end{abstract}

David Widerker fez uma objeção similar. Segundo Widerker, "o sucesso do caso de Frankfurt contra PPA depende da sua capacidade para nos convencer da plausibilidade" do seguinte princípio: podem existir circunstâncias que não deixam alternativa de ação para a pessoa, mas que apesar disso não a forçam a agir de uma determinada maneira (WIDERKER, 1995, p. 248).

Widerker nos pede para considerar o seguinte caso de tipo Frankurt. Jones está deliberando se deveria ou não matar Smith em $t_{3}$. Black estaria preparado para coagir Jones a matar Smith, caso ele decidisse, em $t_{2}$, não o matar por razões próprias. Black deveria observar o sinal prévio, presente em $t_{1}$, para saber se ele precisará interferir ou não. Para melhor compreender o cenário de Frankfurt, Widerker o descreve em termos mais concretos:

FONSECA, Tania Schneider da. O princípio das possibilidades alternativas. Griot : Revista de Filosofia, Amargosa - BA, v.19, n.2, p.230-249, junho, 2019. 
(1) Se Jones está corando em $t_{1}$, então desde que ninguém intervenha, Jones decidirá, em $t_{2}$, matar Smith.

(2) Se Jones não está corando em $t_{1}$, então desde de que ninguém interfira, ele não decidirá, em $t_{2}$, matar Smith.

(3) Se Black percebe que Jones mostra o sinal de que não decidirá, em $t_{2}$, matar Smith, isto é, se ele percebe que Jones não está corando em $t_{1}$, então Black força Jones a decidir, em $t_{2}$, matar Smith; mas se ele vê que ele está corando em $t_{1}$, ele não faz nada.

Finalmente, suponha que Black não intervenha, porque:

(4) Jones está corando em $t 1$ e decide, em $t 2$, matar Smith por razões próprias (WIDERKER, 1995, p. 249-250).

O problema estaria na premissa (1), segundo Widerker. Os defensores dos exemplos de tipo Frankfurt precisariam enfrentar o desafio do dilema. Por um lado, supondo a verdade da tese determinista, a relação entre o sinal neurológico prévio, em $t_{1}$, e a decisão, em $t_{2}$, seria causalmente suficiente. Então, o princípio acima falharia visto que a decisão de Jones seria determinada, portanto, ele não estaria, em $t_{2}$, decidindo livremente. Por outro lado, pressupondo o indeterminismo, não existindo a relação de causalidade entre o sinal, em $t_{1}$, e a decisão, em $t_{2}$, então seria "difícil ver como a decisão de Jones é inevitável" (WIDERKER, 1995, p. 251). Sendo assim, seria preservado o poder de Jones de decidir não matar Smith. Para esse raciocínio, os contraexemplos de tipo Frankfurt não teriam sucesso em mostrar a falsidade do PPA quando aplicado a estados mentais tais como escolhas, decisões ou volições: "nós podemos dizer que um interventor contrafactual de tipo Frankfurt poderia privar um agente da liberdade de executar um determinado desejo ou intenção, mas ele não poderia impedi-lo da sua liberdade de formá-lo" (WIDERKER, 1995, p. 255).

Já Stewart Goetz sustenta que nós estaríamos sendo distraídos pelo mecanismo filosófico (tanto de Frankfurt como dos defensores do compatibilismo de tipo Frankfurt) quando é dito que Black estaria desempenhando a tarefa de eliminar as possibilidades alternativas. Porém, isso seria uma ilusão porque seria o determinismo causal, e não Black e seu dispositivo, que suprimiria o tipo de controle metafísico em discussão. Vejamos esse ponto mais especificamente:

[O exemplo de tipo Frankfurt] cria a aparência que é o dispositivo de Black, que está na sequência alternativa dos eventos, que faz com que Jones não seja livre para fazer de outro modo. Esta aparência é ilusória porque sem a ocorrência do determinismo causal na sequência real dos eventos, o dispositivo não pode impedir Jones de fazer uma escolha alternativa, e com determinismo causal na sequência real dos eventos, não é o dispositivo que impede Jones de fazer uma escolha alternativa. Em resumo, se Jones não é livre para fazer de outro modo, é por causa da ocorrência do determinismo causal na sequência real dos eventos, e não por causa do dispositivo de Black na sequência alternativa. Portanto, é errado concluir que Jones é moralmente responsável embora ele não seja livre para escolher de outro modo (GOETZ, 2005, p. 85).

FONSECA, Tania Schneider da. O princípio das possibilidades alternativas. Griot : Revista de Filosofia, 
$O$ que faz com que Jones fosse incapaz de escolher de outro modo, em $t_{2}$, seria o estado anterior do universo, em $t_{1}$, e as leis da natureza. Black e o seu dispositivo são nesse caso impotentes. Dito de outro modo, seria unicamente por causa da suposição de uma relação causalmente determinista, presente na sequência real, que a possibilidade de Jones de começar a escolher diferentemente seria eliminada. Se a tese do determinismo causal fosse falsa, então Black e o seu dispositivo não poderiam impedir que Jones escolhesse de outro modo.

A seguir, e para finalizar, procurarei responder as críticas levantadas acima.

\section{Réplica à defesa do dilema}

Terei por foco o dilema que pressupõe o determinismo causal. Eu concordo com a crítica de que, sendo verdadeira a tese determinista, não seria razoável ou justificável assumir que o agente é moralmente responsável pelo seu comportamento, pois seria problemático concluir, somente a partir da análise dos exemplos (de tipo Frankfurt), que o agente é moralmente responsável. Esses casos poderiam ser usados como o primeiro passo de um argumento mais complexo para a compatibilidade do determinismo causal com a responsabilidade. A partir da reflexão sobre eles, seria plausível chegar à conclusão preliminar de que se Jones não é moralmente responsável pela sua escolha e ação, a razão não é simplesmente porque ele careceria de possibilidades alternativas. $\mathrm{O}$ argumento pode ser apresentado como segue:

Isto é, supondo que nós explicitamente assumimos que determinismo causal é verdadeiro, nesses casos é importante primeiro observar que eu não proponho que nós precipitadamente devemos concluir, a partir da mera reflexão sobre os casos, que Jones é moralmente responsável pela sua escolha e ação. Em vez disso, a conclusão inicial é que, se ele não é moralmente responsável, não é porque ele carece de possibilidades alternativas apropriadas (FISCHER, 2010a, p. 323).

Nesse sentido, seria intuitivamente razoável afirmar, como primeiro passo do argumento, que as possibilidades alternativas são irrelevantes para atribuições de responsabilidade moral. Em outras palavras, esses casos forneceriam fortes razões para pensar que responsabilidade não exige a capacidade para agir diferentemente. Se isso se confirmar como justificável, então o segundo passo do argumento consistiria em questionar se dado a verdade do determinismo causal, existiria algum outro fator que desempenharia algum papel, na sequência real, e que ameaçaria a responsabilidade moral (FISCHER, 2002, p. 291-292)16. O desafio agora é outro, não mais sobre a compatibilidade do determinismo com o tipo de controle que envolveria a capacidade do agente para escolher ou agir de outro modo, mas como compatibilizar determinismo com responsabilidade moral na sequência real dos eventos.

\footnotetext{
${ }^{16}$ Se responsabilidade moral não exige o tipo de controle que envolve possibilidades alternativas, então isso abre a possibilidade para uma defesa do semicompatibilismo, mesmo admitindo a solidez do argumento da consequência (FISCHER, 2007, p. 53-82). O agnosticismo é conveniente ao defensor do semicompatibilismo, pois essa posição simplesmente afirma que determinismo causal seria compatível com responsabilidade moral, independentemente se determinismo eliminaria acesso às possibilidades alternativas.
}

FONSECA, Tania Schneider da. O princípio das possibilidades alternativas. Griot : Revista de Filosofia, Amargosa - BA, v.19, n.2, p.230-249, junho, 2019. 
Um dos problemas que o incompatibilista precisaria enfrentar é se no futuro a física vier a descobrir que o determinismo causal é verdadeiro. Sendo o determinismo causal verdadeiro, e o argumento da consequência sólido, então não haveria possibilidades alternativas disponíveis ao agente, nem mesmo um mero átimo de liberdade (FISCHER, 2007, p. 61; FISCHER, 2006, p. 45).

Porém, penso que nós não precisaríamos nos comprometer com essa hipótese. Nos casos de tipo Frankfurt, e no caso original de Frankfurt, por exemplo, existem, pelo menos, dois fatores que tornariam plausível afirmar que Jones carece do tipo relevante de acesso metafísico genuíno às possibilidades alternativas: Black e seu dispositivo, por um lado, e a suposição do determinismo causal, por outro. No entanto, esses fatores não teriam desempenhado nenhum papel na sequência real dos eventos. Portanto, não teriam afetado a responsabilidade moral do agente.

A conclusão inicial, como dito anteriormente, de que se Jones não fosse moralmente responsável não seria porque ele careceria de possibilidades alternativas, tem recebido uma série de objeções. Uma dessas objeções, já mencionada anteriormente, foi feita por Goetz, o qual teria imputado a Frankfurt, e aos defensores dos casos de tipo Frankfurt, o uso de mecanismos para nos distrair e nos iludir ao sustentarem que Black e o seu dispositivo neurológico seriam as causas da eliminação das possibilidades alternativas. Para Goetz, não seria nem Black nem o seu dispositivo, mas a relação causalmente determinística entre o estado do universo, em $t_{1}$, e a escolha de Jones, em $t_{2}$, que eliminaria a possibilidade de Jones de começar a escolher diferentemente.

Acredito que Frankfurt talvez possa responder à crítica de Goetz. Em uma interessante nota de rodapé estaria um alerta sobre o papel de Black:

\begin{abstract}
O exemplo é [...] flexível suficiente para permitir a eliminação de Black completamente. Alguém que pensa que a eficácia do exemplo é enfraquecida pela sua dependência de um manipulador humano, que impõe sua vontade sobre Jones, pode substituir Black por uma máquina programada para fazer o que Black faz. Se isso ainda não é bom suficiente, esqueça Black e a máquina, e suponha que seu papel é desempenhado por forças naturais que não envolve nenhuma vontade (FRANKFURT, 1998, p. 7 , nota n.4).
\end{abstract}

A objeção de que seria o determinismo causal e não Black que eliminaria as possibilidades alternativas é controversa. Como argumentado por Fischer, "não é claro que o mero fato de que um estado anterior do universo (em conjunto com as leis da natureza) explica por que Jones não poderia em $t_{2}$ escolher de outro modo implica que nenhum outro fator pode desempenhar esse tipo de papel explicativo" (FISCHER, 2010a, p. 332).

Black e o seu dispositivo seriam suficientes para impedir Jones de escolher ou agir diferentemente. Mas intuitivamente esses fatores seriam irrelevantes para a responsabilidade moral de Jones, na medida em que Black não teria desempenhado qualquer papel na sequência real das deliberações ou ações de Jones. Quando algum fator é irrelevante para o que acontece na sequência real em que resultam as escolhas e ações do agente, parece razoável concluir que esse fator é também irrelevante para a responsabilidade moral (FISCHER, 2007, p. 60).

FONSECA, Tania Schneider da. O princípio das possibilidades alternativas. Griot : Revista de Filosofia, Amargosa - BA, v.19, n.2, p.230-249, junho, 2019. 
As premissas do argumento para a compatibilidade do determinismo causal com responsabilidade moral poderiam ser formuladas da seguinte maneira: suponha que a tese determinista seja verdadeira, que a presença de Black (e o seu dispositivo) eliminaria a liberdade do agente para escolher ou agir diferentemente. Se Jones não é moralmente responsável por escolher ou agir, não seria em virtude do mero fato de que ele não tinha possibilidades alternativas. Se o determinismo exclui a responsabilidade moral não seria em virtude de eliminar as possibilidades alternativas (FISCHER, 2010a, p. 328).

Enfim, são dois tipos distintos de argumentos incompatibilistas. Um deles, o argumento indireto, sustentaria que o determinismo é incompatível com a responsabilidade moral, pois o determinismo eliminaria as possibilidades alternativas. O outro, o argumento direto, defenderia que o determinismo é incompatível com a responsabilidade, mesmo supondo que a responsabilidade não exige a capacidade para escolher ou agir diferentemente. Neste artigo eu pretendi discutir apenas a questão da não necessidade da capacidade para agir de outro modo para responsabilizar moralmente o agente. 


\section{Referências:}

BOK, Hillary. Freedom and Responsibility. Princeton: Princeton University Press, 1998.

BLUMENFELD, David. The Principle of Alternate Possibilities. The Journal of Philosophy, v. 68, n. 11, p. 339-345, 1971.

CHISHOLM, Roderick. Human Freedom and the Self. In: WATSON, Gary (org.). Free Will. 2nd Edition. Oxford: Oxford University Press, 2013, p. 26-37.

FISCHER, John. My Way: Essays on Moral Responsibility. New York: Oxford University Press, 2006.

FISCHER, John. Responsibility and Control. The Journal of Philosophy, v. 79, n. 1, p. 24-40, 1982.

FISCHER, John. Recent Work on Moral Responsibility. Ethics, v. 110, n. 1, p. 93$139,1999$.

FISCHER, John. The Frankfurt Cases: The Moral of the Stories. Philosophical Review, v. 119, n. 3, p. 315-336, 2010a.

FISCHER, John. Frankfurt-type Examples and Semi-Compatibilism. In: KANE, Robert. (org.). The Oxford Handbook of Free Will. Oxford: Oxford University Press, 2002, p. 281-308.

FISCHER, John; KANE, Robert; PEREBOOM, Derk; VARGAS, Manuel. Four Views on Free Will. Oxford: Blackwell Publishing, 2007.

FRANKFURT, Harry. The Importance of What We Care About. Cambridge: University Press, 1998.

FRANKFURT, Harry. Alternate Possibilities and Moral Responsibility. In: FRANKFURT, Harry. The Importance of What We Care About. New York: Cambridge University Press, 1998, p. 1-10.

GINET, Carl. In Defense of the Principle of Alternative Possibilities: Why I Don't Find Frankfurt's Argument Convincing. Philosophical Perspectives, v. 10, p. 403$417,1996$.

GOETZ, Stewart. Frankfurt-Style Counterexamples and Begging the Question. Midwest Studies in Philosophy, v. 29, n. 1, p. 83-105, 2005.

HORGAN, Terence. 'Could', Possible Worlds, and Moral Responsibility. Southern Journal of Philosophy, v. 17, n. 3, p. 345-358, 1979.

HORGAN, Terence. Compatibilism and the Consequence Argument. Philosophical Studies, v. 47, n. 3, p. 339-356, 1985.

KANE, Robert. The Significance of Free Will. New York: Oxford University Press, 1998.

KANE, Robert. Free Will and Values. New York: Albany State University of New York Press, 1985.

KANE, Robert. Responsibility, Luck, and Chance: Reflections on Free Will and Indeterminism. In: WATSON, Gary (org.). Free Will. 2nd Edition. Oxford: Oxford University Press, 2013, p. 299-321.

LEWIS, David. Are We Free to Break the Laws? Theoria, v. 47, p. 113-121, 1981.

VAN INWAGEN, Peter. An Essay on Free Will. Oxford: Clarendon Press, 1983.

VAN INWAGEN, Peter. Ability and Responsibility. The Philosophical Review, v. 87, n. 2, p. 201-224, 1978. 
WIGGINS, David. Towards a Reasonable Libertarianism. In: WATSON, Gary (org.). Free Will. 2nd Edition. Oxford: Oxford University Press, 2013, p. 94-121.

WYMA, Keith. Moral Responsibility and Leeway for Action. American Philosophical Quarterly, v. 34, n. 1, p. 57-70, 1997.

WIDERKER, David. Libertarianism and Frankfurt's Attack on the Principle of Alternative Possibilities. The Philosophical Review, v. 104, n. 2, p. 247-261, 1995.

Autor(a) para correspondência: Tania Schneider da Fonseca, Universidade do Vale do Rio dos Sinos, Av. Unisinos, 950, Cristo Rei, 93022-750, São Leopoldo - RS, Brasil. taniaschneider.fonseca@gmail.com. 